American Journal of Agricultural and Biological Sciences 5 (1): 50-55, 2010

ISSN 1557-4989

(C) 2010 Science Publications

\title{
A Review: The Role of Remote Sensing in Precision Agriculture
}

\author{
S. Liaghat and S.K. Balasundram \\ Department of Agriculture Technology, Faculty of Agriculture, \\ University Putra Malaysia, 43400 Serdang, Selangor, Malaysia
}

\begin{abstract}
Precision agriculture is an emerging farm management strategy that is changing the way people farm. At present, there is an increasing commitment to reduce reliance on excessive chemical inputs in agriculture. Numerous technologies have been applied to make agricultural products safer and to lower their adverse impacts on the environment, a goal that is consistent with sustainable agriculture. Precision agriculture has emerged as a valuable component of the framework to achieve this goal. This review highlights on remote sensing technology and describes how it can be used as an effective tool in precision agriculture.
\end{abstract}

Key words: Sustainable agriculture, environment, remotely sensed data, spectral reflectance

\section{INTRODUCTION}

Since the Industrial Revolution, agriculture practices in developed countries have tended to support greater energy inputs using large machineries and increased applications of chemicals and fertilizers. While these practices have negative societal and environmental implications such as soil erosion and salinization, soil fertility, compaction of subsoils and soil/water pollution, they have generally supported the food and fiber needs of a rapidly growing human population. A paradigm shift toward a new production method that ensures safe and sustainable agriculture is needed. Across the globe, Precision Agriculture (PA) is changing the way people farm as it offers a myriad of potential benefits in profitability, productivity, sustainability, crop quality, environmental protection, on-farm quality of life, food safety and rural economic development. PA is an innovative, integrated and internationally standardized approach aiming to increase the efficiency of resource use and to reduce the uncertainty of decisions required to manage variability on farms. PA has been hailed as one of the most scientific and modern approaches to production agriculture in the 21 st century, as it epitomizes a better balance between reliance on traditional knowledge and information and management-intensive technologies. At present, there is an increasing commitment to reduce reliance on excessive chemical inputs in agriculture. Numerous technologies have been applied to make agricultural products safer and to lower their adverse impacts on the environment, a goal that is consistent with sustainable agriculture. PA has emerged as a valuable component of the framework to achieve this goal (Kropff et al., 1997; Tellaeche et al., 2008; Zhang et al., 2002).

PA is an integrated, information- and productionbased farming system that is designed to increase long term, site-specific and whole farm production efficiency, productivity and profitability while avoiding the undesirable effects of excess chemical loading to the environment or productivity loss due to insufficient input application. The inference is that better decision making will provide a wide range of benefits in economic, environmental and social aspects that may or may not be known or measurable at present (Auernhammer, 2001). Worldwide, investments in research and technology development on PA have considerably increased during the past decade (Schellberg et al., 2008).

The importance of PA has been widely recognized as a key contributor in crop production technology around the globe, but so far, this technology is only becoming practicable on large farms. PA is based on innovative systems approach and these new systems approach depends on a combination of fundamental technologies such as Geographic Information System (GIS), Global Positioning System (GPS), computer modeling, ground based/airborne/satellite remote sensing, variable rate technology and advanced information processing for timely in-season and between season crop management. Protocols for PA

Corresponding Author: Siva K. Balasundram, Department of Agriculture Technology, Faculty of Agriculture, University Putra Malaysia, 43400 Serdang, Selangor, Malaysia

Tel: +603-8946 4186 Fax: +603-8946 4146 
implementation can be encapsulated in three general steps: (1) Gathering information about variability, (2) Processing and analyzing information to assess the significance of variability and (3) Implementing change in the management of inputs. PA subscribes to a cyclic process that is typified by a system that gets smarter every year a farm operator uses it. Taken together, this implies that the three general steps may each require a timeframe ranging from months to years so as to collectively generate a stable and workable structure, but yet be subjected to further amendments and refinements. The importance of PA evolved during the era of agricultural mechanization in the 20th century where there was strong economic pressure to treat large fields with uniform agronomic practices. PA provides a means to automate Site-Specific Management (SSM) using information technology, thereby making SSM practical in commercial agriculture (Auernhammer, 2001).

The PA database generally includes (Venkataratnam, 2001):

- Crop information such as growth stage, health, nutrient requirement

- Soil physical and chemical properties, depth, texture, nutrient status, salinity and toxicity, soil temperature, productivity potential

- Microclimatic data (seasonal and daily) such as canopy temperature, wind direction and speed, humidity

- Surface and sub surface drainage conditions

- Irrigation facilities, water availability and planning of other inputs

A PA system that harnesses recent advances in sensor technology can play a crucial role toward an intelligent crop production system. Specifically, remote sensing technology that allows non-destructive acquisition of information about the Earth's surface can facilitate the implementation of PA. For example current crop status (including maturity period) and crop stresses such as nutrient and water stress, disease, pest and weed infestations can be discerned by means of remote sensing instruments such as cameras, laser scanners, linear arrays and area arrays, without actually being in contact with them. Information gathered via different sensors and referenced using a GPS can be integrated to create field management strategies for chemical application, cultivation and harvest. This review highlights on remote sensing technology and describes how it can be used as an effective tool in Precision Agriculture.

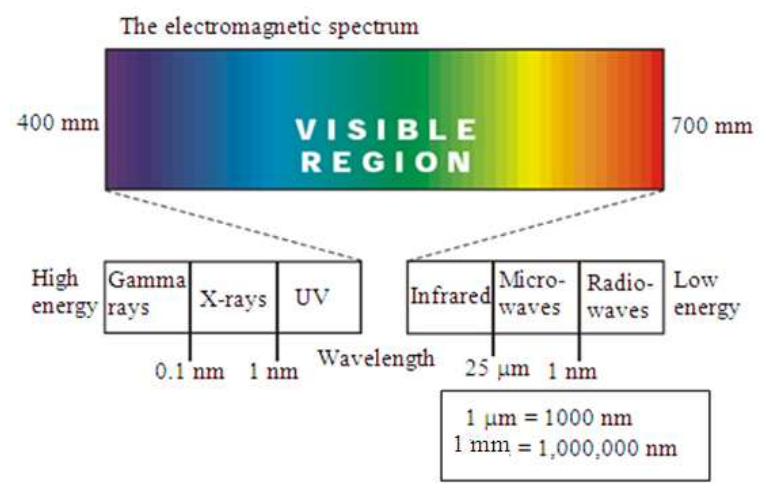

Fig. 1: The visible region of the spectrum ranges from about 0.4-0.7 $\mu \mathrm{m}$ (Nowatzki et al., 2004)

Remote sensing technology: Remote Sensing (RS) is the science of obtaining and interpreting information from a distance, using sensors that are not in physical contact with the object being observed (Jensen, 1996). The science of remote sensing includes aerial, satellite and spacecraft observations of the surfaces and atmospheres of the planets in our solar system, while the Earth is noticeably the most frequent target of study. $\mathrm{RS}$ is usually restricted to methods that detect and measure electromagnetic energy including visible and non-visible radiation that interact with surface materials and the atmosphere (Fig. 1).

RS and GIS technologies have been of great use to planners in planning for efficient use of natural resources at national, state and district levels. Application of these technologies in the management of natural resources are increasing rapidly due to great strides made in space-borne RS satellites in terms of spatial, temporal, spectral and radiometric resolutions (Venkataratnam, 2001).

Remote sensing has several unique advantages (Jensen, 1996):

- $\quad$ RS technology is well-known as a non destructive method to collect information about earth features

- $\quad$ RS data may be obtained systematically over very large geographical areas rather than just single point observations

- $\quad$ RS data can reveal information about places that are inaccessible to human exploration

- The systematic (raster) data collection in RS can remove sampling bias

- RS can provide fundamental biophysical information that can be used in other sciences

- $\mathrm{RS}$ is independent from the data produced elsewhere, in comparison with the other mapping sciences such as cartography or GIS 
The history of modern RS began when black and white photographs of the landscape were first taken from the air. The first utilization of aerial photographs appeared for military purposes. Eventually, the Agriculture Stabilization and Conservation Service adopted the technology and began collecting indexed photographs of the landscape for agricultural purposes. RS, today, incorporates new technologies that provide increasingly efficient, complete, accurate and timely information. Today, RS is potentially a practical management tool for site-specific crop management (Casady and Palm, 2002).

How can remotely-sensed data be used in agriculture? RS technology is a key component of PA and is being used by an increasing number of scientists, engineers and large-scale crop growers. During the last two decades, development in RS data acquisition capabilities, data processing and interpretation of ground based, airborne and satellite observations have made it possible to couple RS technologies and precision crop management systems (Waheed et al., 2006).

Currently, there is a wide range of satellite data that varies in (i) technique (active/passive, radiometer/scatterometer), (ii) spatial resolution from submeter to kilometers (iii) spectral range, and (iv) viewing geometry (Oza et al., 2008). The full commercial availability of very high resolution satellite data has opened up a number of new opportunities for the use of Earth Observation (EO) data. Today, we can perform many applications with EO data that in only the recent past were exclusive to manpower investigation and in situ surveys, which was timeconsuming and hard-sledding, despite the geographic limitations of such data and techniques. Satellite imagery can be acquired over any area globally, in a time frame and at a given price. At present, higher resolution satellite imagery overcomes previous constraints and permits the use of such data as a quick and easy tool for territorial management, including agricultural analysis, statistics and subsidy control. QuickBird is currently the satellite with the highest resolution which is available for agricultural and civilian uses (Fig. 2). The main requirements of QuickBird as a source of information for agricultural and forestry applications is identified in Table 1.

New RS multispectral and hyperspectral sensors are swiftly generating vast amounts of data in a costeffective manner and at higher spatial and spectral resolutions. Hyperspectral and multispectral images, consisting of reflectance from the visible, near infrared and mid-infrared regions of the electromagnetic spectrum, can be interpreted in terms of physical
Table 1: QuickBird satellite imagery specification (Pan et al., 2009) Spatial resolution $\quad 0.61 \mathrm{~m}$ panchromatic resolution and $2.44 \mathrm{~m}$ multispectral resolution at nadir

Spectral resolution Four multispectral bands (three in the visible and one in the near infrared)

Radiometric resolution 11 bit dynamic range (2048 levels of grey)

Temporal resolution A reviewing rate that depends on the off nadir angle. In any case, applications that require multitemporal observation with a seasonal frequency can be easily carried out with QuickBird data

Swath In the range of $16.5-18.0 \mathrm{~km}$

Frame $\quad 270$ up to more than $300 \mathrm{~km}^{2}$

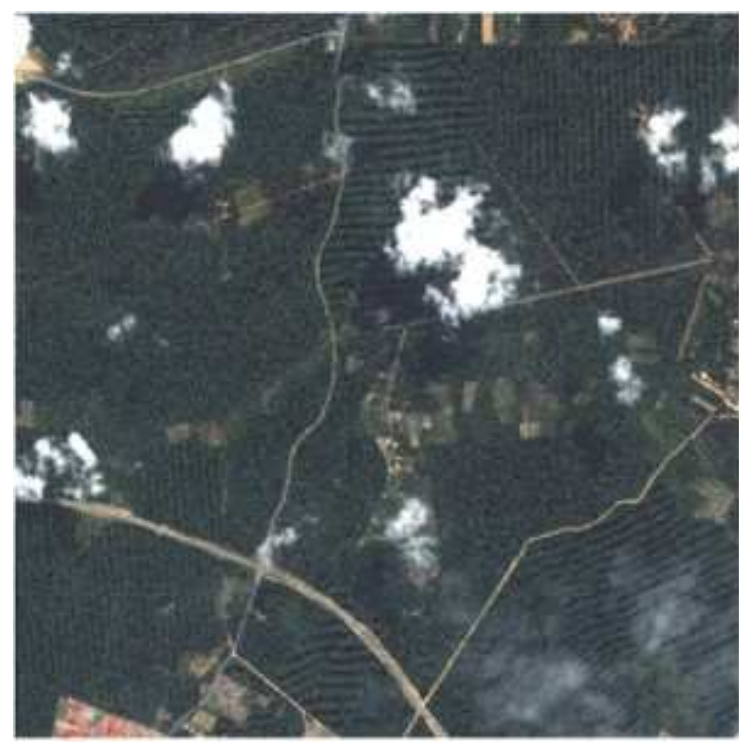

Fig. 2: A QuickBird satellite imagery taken from an oil palm plantation in Merlimau, Melaka, Malaysia

parameters (such as crop cover, crop health and soil moisture) and are useful for operations such as stress mapping, fertilization and pesticide application and irrigation management (Barnes and Baker, 2000; Barroso et al., 2008; Hinzman et al., 1986; Lelong et al., 1998; Pal and Mather, 2003; Singh et al., 2007; Tilling et al., 2007; Yang et al., 2003). Nutrient contents of different crops such as wheat (Lelong et al., 1998; Silva and Beyl, 2005; Tilling et al., 2007), paddy rice (Stroppiana et al., 2008), sorghum (Zhao et al., 2005), corn (Samson et al., 2000), broccoli (Shikha et al., 2007), citrus (Min, 2008), grape (Smart et al., 2007), apple (Perry and Davenport, 2007) have also been assessed using hyperspectral and multispectral RS data. Interpretation of RS data is often aided by specialized techniques such as geostatistics, image analysis and classification, and artificial intelligence.

RS techniques also play an important role in assessing crop condition and yield forecasting, acreage 
estimates of specific crops, detection of crop pests and diseases, disaster location and mapping, wild life management, water supply information and management, weather forecasting, rangeland management, and livestock surveys.

Recently, QuickBird imagery and a Production Efficiency Model (PEM) were used to estimate crop yields in Zhonglianchuan, a hilly area on Loess Plateau, China. In the PEM model, crop yields were a function of the Photosynthetic Active Radiation (PAR), fraction of Absorbed Photosynthetically Active Radiation (fAPAR) and Light Use Efficiency (LUE). Results showed QuickBird imagery can improve the yield estimation accuracy. The information extracted from the image was highly correlated to estimated yields from ground data collection $\left(\mathrm{r}^{2}=0.86\right)$ (Pan et al., 2009).

Some disease and insect pests of crops may be monitored by remote sensing. Riedell et al. (2004) introduced remote sensing technology as an effective and inexpensive method to identify pest-infested and diseased plants. They used remote sensing techniques to detect specific insect pests and to distinguish between insect and disease damage on oat. Results suggested that canopy characteristics and spectral reflectance differences between insect infestation damage and disease infection damage can be measured in oat crop canopies by remote sensing but that these differences may not be consistent from one growing season to the next.

Kurtz et al. (2009) used multi-temporal Landsat imagery in order to classify land cover types and grazing intensity. Grazing intensity categories were defined based on percentage of bare soil, sward height and standing dead material. Correlation analysis between spectral ratio, i.e. Normalized Difference Vegetation Index (NDVI), and above ground biomass, was significant. Meanwhile, Moreau and Toan (2003) utilized Synthetic Aperture Radar (SAR) data to quantify biomass in an Andean wetland for the purpose of optimizing livestock management. The signal sensitivity corresponding to biomass variation was high enough to facilitate high accuracy biomass mapping.

In semi-arid Northeast of Brazil, Folhes et al. (2009) employed Landsat imagery in conjunction with an evapotranspiration model to measure water use levels in an irrigated area. Results showed that the combination approach of RS and process modeling produced better predictability of water consumption in irrigated agriculture, and hence improved water resource management in irrigated areas.

RS also provide useful information to detect and map disaster location. Data from the NASA'S MODIS
(Aqua and Terra) and EUMETSAT'S MSG-SEVIRI satellite sensors were used to characterize fire disaster in Swaziland. Combination of RS and GIS techniques were used to characterize the geographic and temporal (including diurnal) evolution of the July, 2007 fire disaster. Significant fire activity was observed during a three-day period beginning July 27, 2007. A total of 1358 and 4365 active fire hotpots were detected by MODIS and MSG SEVIRI, respectively. Results revealed the potential use of RS and GIS for fire disaster and risk assessment in a developing country, where fire monitoring resources are limited (Dlamini, 2009). Conversely, Yang et al. (2007) demonstrated that satellite-based RS is a very useful method of forecasting heavy rainfall.

RS applications in agriculture have progressed to a stage where information from RS imagery is being used for a number of policy level decisions related to food security, poverty alleviation and sustainable development. Decision on buffer stock of food grains could be based on pre-harvest crop acreage and production estimates while the ground water potential maps serve as a major source of information in ensuring drinking water and other needs in rain-fed and less favorable areas. Nationwide land use, land cover, soil and wasteland mapping have helped in expansion and intensification of agricultural activities and also in identification of land capability classes and crop suitability indices (Venkataratnam, 2001).

\section{CONCLUSION}

With increasing population pressure throughout the world and the need for increased agricultural production, there is a definite need for improved management of the world's agricultural resources. To make this happen, it is first necessary to obtain reliable data on not only the types of resources, but also the quality, quantity and location of these resources. Satellite-or aerial-based RS technologies will become important tools in improving the present system(s) of acquiring and generating agricultural and natural resource data.

Agriculture surveys are presently conducted throughout the world in order to gather empirical information on crops, rangeland, livestock and other agricultural resources. Such information is critical for effective management of depleting and scarce resources. Surveys that are based on the PA concept can facilitate planning and allocation of limited resources to different sectors of the economy. RS technology has the potential of revolutionizing the detection and characterization of agricultural productivity based on 
biophysical attributes of crops and/or soils. Essentially, like other PA components, the information gained from $\mathrm{RS}$ data is more meaningful when used in combination with ground data.

Although RS cannot capture all types of agricultural information, it can reliably provide accurate and timely information to guide agronomic and economic decision-making.

\section{REFERENCES}

Auernhammer, H., 2001. Precision farming-the environmental challenge. Comput. Elect. Agric., 30: 41-33. DOI: 10.1016/S0168-1699(00)00153-8

Barnes, E.M. and M.G. Baker, 2000. Multispectral data for mapping soil texture: Possibilities and limitations. Applied Eng. Agric., 16: 731-741. http://asae.frymulti.com/abstract.asp?aid $=5370 \& \mathrm{t}=1$

Barroso, L.A.M., J.G. Payan and E.R. Vivoni, 2008. Quantifying water stress on wheat using remote sensing in the Yaqui Valley, Sonora, Mexico. Agric. Water Mgmt., 95: 725-736. DOI: 10.1016/j.agwat.2008.01.016

Casady, W.W. and H. L. Palm, 2002. Precision agriculture: Remote sensing and ground truthing. MU Extension, University of Missouri-Columbia. http://extension.missouri.edu/explorepdf/envqual/eq0 453.pdf

Dlamini, W.M., 2009. Characterization of the July 2007 Swaziland fire disaster using satellite remote sensing and GIS. Applied Geogr., 29: 299-307. DOI: 10.1016/j.apgeog.2008.10.007

Folhes, M.T., C.D. Renno and J.V. Soares, 2009. Remote sensing for irrigation water management in the semiarid Northeast of Brazil. Agric. Water Mgmt., 96: 1398-1408. DOI: 10.1016/j.agwat.2009.04.021

Hinzman, L.D., M.E. Bauer and C.S.T. Daughtry, 1986. Effects of nitrogen fertilization on growth and reflectance characteristics of winter wheat. Remote Sens. Environ., 19: 47-61. DOI: 10.1016/00344257(86)90040-4

Jensen, J. R., 1996. Remote sensing of the environment: An Earth Resource Perspective. 3th Edn., Prentice Hall, USA, pp: 1-28.

Kropff, M.J., J. Wallinga and L.A.P. Lotz, 1997. Modelling for Precision Weed Management. In: Precision Agriculture: Spatial and Temporal Variability of Environmental Quality, Lake, J.V., G.R. Bock and J.A. Goode (Eds.). Chichester, Wiley, pp: 182-204.

Kurtz, D.B., J. Schellberg and M. Braun, 2009. Ground and satellite based assessment of rangeland management in sub-tropical Argentina. Applied Geogr. (In Press). DOI: 10.1016/j.apgeog.2009.01.006
Nowatzki, J., R. Andres and K. Kyllo, 2004. Agricultural remote sensing basics. http://www.ag.ndsu.edu/pubs/ageng/gis/ae1262.pdf

Lelong, C.C.D., P.C. Pinet and H. Poilve, 1998. Hyperspectral imaging and stress mapping in agriculture: A case study on wheat in Beauce (France). Remote Sens. Environ., 66: 179-191. DOI: 10.1016/S0034-4257(98)00049-2

Min, M., W.S. Lee, T.F. Burks, J.D. Jordan and A.W. Schumann, 2008. Design of a hyperspectral nitrogen sensing system for orange leaves. Comput. Elect. Agric., 63: 215-226. DOI: 10.1016/j.compag.2008.03.004

Moreau, S. and T.L. Toan, 2003. Biomass quantification of Andean wetland forages using ERS satellite SAR data for optimizing livestock management. Remote Sens. Environ., 84: 477-492. DOI: 10.1016/S00344257(02)00111-6

Oza, S.R., S. Panigrahy and J.S. Parihar, 2008. Concurrent use of active and passive microwave remote sensing data for monitoring of rice crop. Int. J. Applied Earth Obst. Geoinform., 10: 296-304. DOI: 10.1016/j.jag.2007.12.002

Pal, M. and P.M. Mather, 2003. An assessment of the effectiveness of decision tree methods for land cover classification. Remote Sens. Environ., 86: 554-565. DOI: 10.1016/S0034-4257(03)00132-9

Pan, G., G.J. Sun and F.M. Li, 2009. Using QuickBird imagery and a production efficiency model to improve. Environ. Model. Software, 24: 510-516. DOI: 10.1016/j.envsoft.2008.09.014

Perry, E.M. and J.R. Davenport, 2007. Spectral and spatial differences in response of vegetation indices to nitrogen treatments on apple. Comput. Elect. Agric., 59: 56-65. DOI: 10.1016/j.compag.2007.05.002

Riedell, W.E., S.L. Osborne and L.S. Hesler, 2004. Insect pest and disease detection using remote sensing techniques. Proceedings of 7 th International Conference on Precision Agriculture. Minneapolis, MN USA.

http://www.ars.usda.gov/research/publications/Public ations.htm?seq_no_115=166154

Samson, G., N. Tremblay, A.E. Dudelzak, S.M. Babichenko, L. Dextraze and J. Wollring, 2000. Nutrient stress of corn plants: Early detection and discrimination using a compact multiwavelength fluorescent lidar. Proceedings of EARSeL-SIG-Workshop LIDAR, June 16-17, Dresden/FRG, pp: 214-223. http://www.eproceedings.org/static/vol01_1/01_1_sa mson1.pdf 
Schellberg, J., M.J. Hill, R. Gerhards, M. Rothmund and M. Braun, 2008. Precision agriculture on grassland: Applications, perspectives and constraints. Eur. J. Agron., 29: 59-71. DOI: 10.1016/j.eja.2008.05.005

Shikha, D.M.E., P. Waller, D. Hunsaker, T. Clarke and E. Barnes, 2007. Ground based remote sensing for assessing water and nitrogen status of broccoli. Agric. Water Mgmt., 92: 183-193. DOI: 10.1016/j.agwat.2007.05.020

Silva, T.A. and C.A. Beyl, 2005. Changes in spectral reflectance of wheat leaves in response to specific macronutrient deficiency. Adv. Space Res., 35: 305-317. DOI: 10.1016/j.asr.2004.09.008

Singh, D., Sao, R. and Singh, K.P. 2007. A remote sensing assessment of pest infestation on sorghum. Adv. Space Res., 39: 155-163. DOI: 10.1016/j.asr.2006.02.025

Smart, D.R., M.L. Whiting and C. Stockert, 2007. Remote sensing of grape $\mathrm{K}$ deficiency symptoms using leaf level hyperspectral reflectance. Proceedings of Western Nutrient Management Conference, March 68, Salt Lake City, UT., pp: 19-24. http://cropandsoil.oregonstate.edu/sites/default/files/ WERA103/2007_Proceedings/WNMC07.p19.Smart.p df

Stroppiana, D., M. Boschetti, P.A. Brivio and S. Bocchi, 2008. Plant nitrogen concentration in paddy rice from field canopy hyperspectral radiometry. Field Crop Res., 111: 119-129. DOI: 10.1016/j.fcr.2008.11.004

Tellaeche, A., X.P. BurgosArtizzu, G. Pajares, A. Ribeiro and C.F. Quintanilla, 2008. A new vision-based approach to differential spraying in precision agriculture. Comput. Elect. Agric., 60: 144-155. DOI: 10.1016/j.compag.2007.07.008

Tilling, A.K., G.J. O'Leary, J.G. Ferwerda, S.D. Jones, and G.J. Fitzgerald, 2007. Remote sensing of nitrogen and water stress in wheat. Field Crop Res., 104: 77-85. DOI: 10.1016/j.fcr.2007.03.023
Venkataratnam, L., 2001. Remote sensing and GIS in agricultural resources management. Proceedings of the 1st National Conference on Agro-Informatics, June 3-4, Dharwad, India, pp: 20-29. http://www.insait.org/abstracts.pdf

Waheed, T., R.B. Bonnell, S.O. Prasher and E. Paulet, 2006. Measuring performance in precision agriculture: CART-A decision tree approach. Agric. Water Mgmt., 84: 173-185. DOI: 10.1016/j.agwat.2005.12.003

Yang, C.C., S.O. Prasher, P. Enright, C. Madramootoo and M. Burgess, 2003. Application of decision tree technology for image classification using remote sensing data. Agric. Syst., 76: 1101-1117. DOI: 10.1016/S0308-521X(02)00051-3

Yang, Y., H. Lin, Z. Guo and J. Jiang, 2007. A data mining approach for heavy rainfall forecasting based on satellite image sequence analysis. Comput. Geosci., 33: 20-30. DOI: 10.1016/j.cageo.2006.05.010

Zhang, N., M. Wang and N. Wang, 2002. Precision agriculture: A worldwide overview. Comput. Elect. Agric., 36: 113-132. DOI: 10.1016/S01681699(02)00096-0

Zhao, D., K.R. Reddy, V.G. Kakani and V.R. Reddy, 2005. Nitrogen deficiency effects on plant growth, leaf photosynthesis and hyperspectral reflectance properties of sorghum. Eur. J. Agron., 22: 391-403. DOI: 10.1016/j.eja.2004.06.005 